\title{
Sistem Informasi Distribusi Cabai Dengan Metode Distribution Requirements Planning (DRP) di Provinsi Jawa Timur
}

\author{
Nur Kholis Mansur ${ }^{1}$, Saiful Bukhori ${ }^{2}$, Oktalia Juwita ${ }^{3}$ \\ Program Studi Sistem Informasi \\ Fakultas Ilmu Komputer \\ Universitas Jember \\ 1nurkholis.mansur@gmail.com, 22saiful.ilkom@unej.ac.id, ${ }^{3}$ oktalia.juwita@gmail.com
}

\begin{abstract}
ABSTRAK
Produksi cabai di Jawa Timur pada tahun 2016 hampir tembus 2 juta ton dengan rincian cabai rawit 1 juta ton dan cabai besar 939 ribu ton. Jumlah produksi cabai yang cukup melimpah tersebut masih menjadi penyebab inflasi. Faktor inflasi disebabkan oleh beberapa faktor, salah satunya jumlah produksi cabai melimpah namun terjadi pada bulan tertentu atau penyebab lainnya adalah pendistribusian yang tidak merata. Pusat produksi cabai di Jawa Timur masih mengalami masalah aktivitas distribusi dalam memenuhi permintaan cabai setiap kota. Pengiriman yang dilakukan di Jawa Timur juga belum memiliki nilai optimal untuk memenuhi jumlah permintaan. Rencana pengiriman yang belum baik juga menyebabkan kesalahan dalam mengatur persediaan untuk melakukan pengiriman. Pemerintah Jawa Timur memerlukan cara untuk menganalisa pendistribusian cabai dengan melakukan perencanaan penjadwalan untuk meningkatkan kemampuan dalam memenuhi permintaan cabai menggunakan metode Distribution Requirement Planning (DRP). Perencanaan menggunakan metode DRP ini dapat menghasilkan analisa kebutuhan kotor dan kebutuhan besih cabai pada tiap kota dengan tingkat service level yang digunakan dalam safety stock adalah 90\%, dengan tabel distribusi normal yaitu sebesar 1,28.
\end{abstract}

Kata Kunci: Supply Chain Management, Distribution Requirements Planning, Distribusi

\begin{abstract}
Chili production in East Java in 2016 reached nearly 2 million tons with details of 1 million tons of chili and large chili 939 thousand tons. The abundant amount of chili production is still the cause of inflation. The inflation factor is caused by several factors, one of which is the abundant amount of chili production but occurs in certain months or other causes are uneven distribution. The chili production center in East Java is still experiencing problems with distribution activities in meeting the demands of chili every city. Shipments carried out in East Java also do not have an optimal value to meet the number of requests. The poor delivery plan also caused errors in arranging inventory to make deliveries. The East Java government needs a way to analyze the distribution of chili by planning scheduling to improve the ability to fulfill chili demand using the Distribution Requirement Planning (DRP) method. Planning using this DRP method can produce an analysis of the gross needs and needs of chili in each city with the level of service used in the safety stock is $90 \%$, with a normal distribution table that is equal to 1.28.
\end{abstract}

Keyword: Supply Chain Management, Distribution Requirements Planning, Distribution

\section{Pendahuluan}

Cabai (Capsicum annuum L.) merupakan salah satu komoditas sayuran yang memiliki nilai ekonomis penting dan tingkat konsumsi tinggi di Indonesia. Jumlah konsumsi cabai dan hasil produksi dari tahun 2013 hingga 2016 terus meningkat. Produksi cabai pada tahun 2016 berdasarkan data Badan Pusat Statistika Jawa Timur hampir tembus 2 juta ton dengan rincian cabai rawit 1 juta ton dan cabai besar 939 ribu ton. Hasil produksi cabai tersebut tersebar di Pulau Jawa, dimana provinsi Jawa Timur menjadi sentra penghasil cabai terbesar di Indonesia.

Jawa Timur menjadi produksi cabai rawit peringkat pertama selama tahun 2013-2015. Tahun 2013 kontribusinya sebesar 31,88\%, sedangkan pada tahun 2015 mengalami penurunan menjadi 28,73\%. Meskipun kontribusi jumlah produksi yang tinggi, cabai masih menjadi penyebab inflasi di Jawa Timur. Faktor inflasi disebabkan oleh beberapa faktor, salah satunya jumlah produksi cabai melimpah namun terjadi pada bulan tertentu atau penyebab lainnya adalah pendistribusian yang tidak merata. Permasalahan tersebut membutuhkan solusi yang efektif dan optimal, agar jumlah produksi cabai tiap daerah bisa didistribusikan dan jumlah permintaan bisa terpenuhi dengan baik. Untuk mengatasinya diperlukan model optimasi distribusi cabai dengan menggunakan beberapa parameter model yakni pendataan jumlah produksi, perencanaan distribusi, dan pendataan nilai akurasi permintaan cabai di wilayah Provinsi Jawa Timur. 
Optimalisasi distribusi produk cabai akan lebih efisien dan terkoordinasi lebih efektif menggunakan metode Distribution Requirements Planning (DRP). DRP adalah sebuah metode yang digunakan untuk menentukan permintaan dan memenuhi persediaan pada pusat-pusat distribusi, menggabungkan permintaan historis sebagai input untuk sistem produksi dan material [2]. Penelitian sebelumnya metode DRP ini digunakan untuk menghasilkan solusi dengan melakukan optimasi persediaan produk dan permintaan. Distribusi produk menggunakan metode DRP untuk permintaan yang akan datang akan bekerja lebih efisien. Penggunaan DRP menjalankan koordinasi dengan yang baik secara berkala agar pengiriman produk untuk tiaptiap tujuan berjalan lebih efektif dan optimal dalam memenuhi permintaan [3]. Metode DRP menjadi salah satu cara untuk membantu merencanakan aktivitas distribusi dan penjadwalan dimana dengan metode ini dapat menetapkan kebutuhan alokasi persediaan dan memastikan bahwa pemenuhan sumber akan dapat memenuhi permintaan. DRP juga memiliki fungsi objektif dalam pengelolaan stok dan operasi pemenuhan permintaan.

\section{Metode Penelitian}

Metode penelitian menggunakan System Development Life Cycle (SDLC) model waterfall. Model waterfall adalah pendekatan secara sitematis dan urut mulai dari analisis, desain, penulisan kode, pengujian, dan pemeliharaan [4]. Tahapan waterfall dapat dilihat pada Gambar 1.

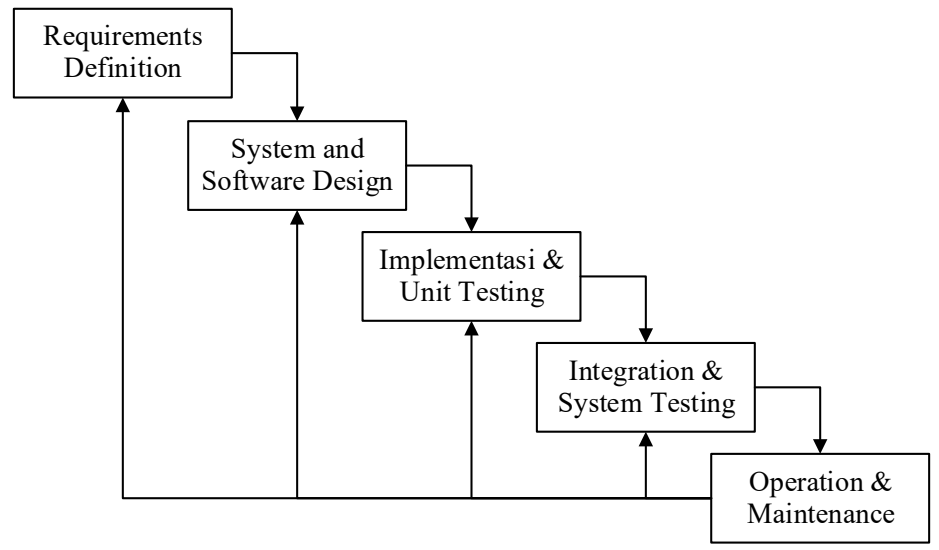

Gambar 1. Model Waterfall

Metode waterfall pada sistem informasi distribusi cabai digunakan untuk melakukan rangkaian kegiatan pada tahapan penelitian dan pengembangan sistem menggunakan metode DRP, dimana dalam analisa kebutuhan hingga implementasi sistem membutuhkan cara sistematis untuk menghasilkan nilai analisa DRP.

\section{Analisa dan Hasil}

Analisa kebutuhan dan hasil pengolahan data cabai pada teori yang diterapkan dalam pengembangan sistem menggunakan metode DRP meliputi kebutuhan fungsional dan kajian teori untuk mendapatkan persamaan agar mudah melakukan perhitungan.

\subsection{Kebutuhan Fungsional dan Non-fungsional}

Pada analisis kebutuhan terdapat kebutuhan fungsional dan kebutuhan non fungsional. Kerikut adalah kebutuhan fungsional sistem:

a. Sistem mampu mengelola data produktivitas lahan cabai (create, view, edit, dan delete).

b. Sistem mampu mengelola data konsumsi cabai (create, view, edit, dan delete).

c. Sistem mampu mengelola data jenis cabai (create, view, edit, dan delete).

d. Sistem mampu mengelola data kab/kota (create, view, edit, dan delete).

e. Sistem mampu mengelola data user (create, view, edit, dan delete).

f. Sistem mampu melakukan kalkulasi distribusi cabai dengan metode DRP.

Kebutuhan non-fungsional pada sistem informasi distribusi cabai meliputi bahasa komunikasi dalam sistem mudah dimengerti oleh pengguna dan desain tampilan sistem yang user friendly, serta aplikasi bisa diakses beberapa user/multiuser.

\subsection{Distribution Requirements Planning (DRP)}

Tahapan analisis kebutuhan lainnya adalah mencari formula persamaan DRP yang digunakan untuk menghasilkan nilai analisa distribusi cabai. Komponen-komponen pada logika dasar yang digunakan untuk perhitungan metode DRP adalah sebagai berikut [5]:

a. On Hand Balance: total persedian yang dimiliki pada awal periode tertentu yang akan digunakan pada periode selanjutnya.

b. Lead time (L): tenggang waktu yang dibutuhkan sejak dilakukan pemesanan suatu item sampai item tersebut siap digunakan. 
c. Safety Stock: adalah stok pengaman atau penentuan penambahan penyimpanan persediaan sebagai bahan patokan untuk mengatasi adanya fluktuasi permintaan (demand) yang memiliki persamaan SS=Z $\alpha$ x $\mathrm{x}$ $\sqrt{ } L$, dimana nilai $Z \alpha$ (tingkat pelayanan) adalah hasil dari perhitungan standar deviasi.

d. Lot Sizing: kuantitas pemesanan yang menyatakan berapa banyak item yang harus dipesan serta teknik lot sizing apa yang harus dipakai.

e. $\quad$ Planned Shipment-ship date: adalah perencanaan pengiriman pada waktu sumber persediaan mengirim suatu item agar item yang dipesan tersebut dapat tersedia pada saat dibutuhkan, dan perencanaan persediaan ini disesuaikan dengan lead time-nya.

\subsection{Business Process}

Business process merupakan diagram yang menggambarkan data yang dibutuhkan oleh sistem. Business process dapat dilihat pada Gambar 2.

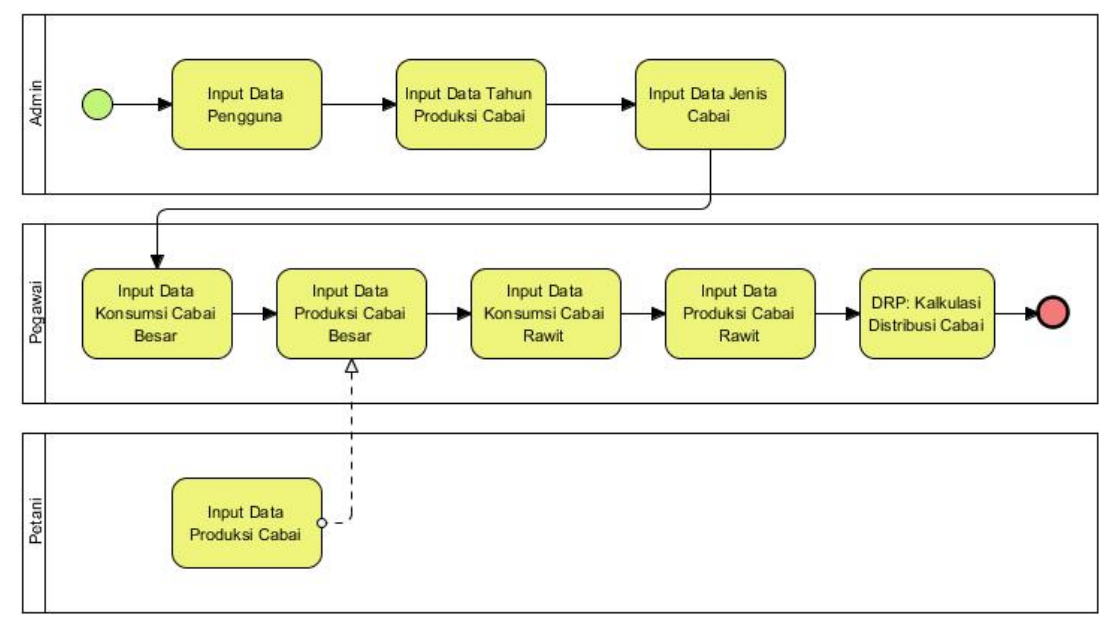

Gambar 2. Bussiness Process

\subsection{Hasil Pengolahan Data Produksi Cabai}

Pengolahan data cabai mengikuti pola produksi yang didefinisikan sebagai distribusi jumlah produksi tahunan dalam periode lebih pendek dalam satu tahun dengan rincian data hasil olahan tiap bulan. Pola produksi yang didapatkan dalam hasil analisa yaitu pola produksi bergelombang dimana jumlah produksi untuk setiap satuan waktu dalam satu tahun tidak selalu sama. Data produksi dijadikan sebagai data olahan untuk menentukan jumlah persediaan cabai di Jawa Timur, maka pola optimal yang digunakan adalah menentukan seberapa banyak jumlah produksi tiap bulan yang mampu memenuhi jumlah permintaan cabai.

\begin{tabular}{|c|c|}
\hline Bulan & Blitar \\
\hline Januari 2015 & 4024,56 ton \\
\hline Februari 2015 & 3074,14 ton \\
\hline Maret 2015 & 3012,43 ton \\
\hline April 2015 & 3234,32 ton \\
\hline Mei 2015 & 3043,42 ton \\
\hline Jun 2015 & 4304,21 ton \\
\hline Juli 2015 & 3023,18 ton \\
\hline Agustus 2015 & 3373,34 ton \\
\hline September 2015 & 3154,25 ton \\
\hline Oktober 2015 & 3238,76 ton \\
\hline November 2015 & 3574,28 ton \\
\hline Desember 2015 & 3437,11 ton \\
\hline Total & 40.494 ton \\
\hline
\end{tabular}

\subsection{Hasil Pengolahan Data Konsumsi Cabai}

Pengolahan data konsumsi cabai didefinisikan sebagai jumlah permintaan tahunan dalam periode lebih pendek dalam satu tahun dengan rincian data konsumsi tiap bulan. Model konsumsi yang didapatkan dalam hasil analisa yaitu model konsumsi bergelombang dimana jumlah konsumsi untuk setiap satuan waktu dalam satu tahun tidak selalu sama. Data konsumsi dijadikan sebagai data olahan permintaan cabai, maka model efektif untuk menentukan jumlah kebutuhan kotor, kebutuhan bersih, serta jadwal rencana penerimaan dan jadwal rencana pelepasan kebutuhan konsumsi untuk wilayah distribusi di Jawa Timur. 
Tabel 2. Hasil Pengolahan Data Konsumsi Cabai Rawit

\begin{tabular}{ll}
\hline Bulan & Blitar \\
\hline Januari 2015 & 3096,65 ton \\
\hline Februari 2015 & 2923,43 ton \\
\hline Maret 2015 & 2975,59 ton \\
\hline April 2015 & 3195,45 ton \\
\hline Mei 2015 & 2952,34 ton \\
\hline Jun 2015 & 2654,44 ton \\
\hline Juli 2015 & 2897,62 ton \\
\hline Agustus 2015 & 2893,41 ton \\
\hline September 2015 & 2984,23 ton \\
\hline Oktober 2015 & 2814,57 ton \\
\hline November 2015 & 2967,76 ton \\
\hline Desember 2015 & 2965,51 ton \\
\hline Total & $\mathbf{3 5 . 3 2 1}$ ton \\
\hline
\end{tabular}

Provinsi Jawa Timur menentukan bahwa target pengiriman pada cabai pada setiap kab/kota adalah sebesar $90 \%$ dari jumlah permintaan. Sehingga tingkat service level yang dipergunakan dalam safety stock adalah 90\% yang berarti nilai S dapat ditentukan dengan melihat tabel distribusi normal yaitu sebesar 1,28 [8]. Adapun untuk melakukan perhitungan safety stock, maka harus menentukan standar deviasi menggunakan persamaan sebagai berikut:

$$
\operatorname{STDEV}=\sqrt{\frac{\sum_{i=0}^{n}(d-\bar{d})^{2}}{n}}
$$

dimana:

d : tingkat permintaan

n : jumlah bulan lead time kota Blitar.

Contoh perhitungan standar deviasi untuk dari data konsumsi dan rata-rata konsumsi cabai rawit pada

$$
\mathrm{STDEV}=\sqrt{\frac{\sum_{i=0}^{n}(d-\bar{d})^{2}}{n}}
$$

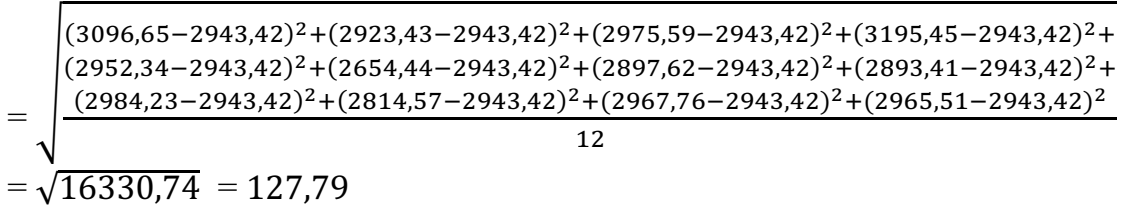

Hasil perhitungan safety stock cabai besar di Blitar dengan standar deviasi yang dihasilkan adalah sebagai berikut:

$\begin{array}{ll}\mathrm{Z} \alpha & =127,79 \\ \mathrm{~L} & =5 \text { hari } \\ \mathrm{S} & =1,28 \\ \text { Sehingga } & \\ \text { Safety Stock } & =\mathrm{Z} \alpha \times \mathrm{S} \times \sqrt{L} \\ & =1,28 \times 127,79 \times \sqrt{5} \\ & =365,76 \text { ton }\end{array}$
berikut [6]:

Persamaan untuk melakukan perhitungan analisa menggunakan metode DRP dengan formula sebagai

Kebutuhan Kotor

Persediaan Di tangan

Kebutuhan Bersih

Jadwal Penerimaan

Pelepasan Rencanan Pemesanan

Contoh perhitungan DRP untuk kota Blitar dengan jenis produksi cabai besar dan konsumsi cabai dapat dilihat pada tabel berikut:

Tabel 3. Analisa Perhitungan DRP Cabai Rawit

\begin{tabular}{ll|l|ll}
\hline \multicolumn{5}{c}{ Blitar } \\
\hline Persediaan Di tangan & $: 3024,56$ & & Safety Stock & $: 365,76$ \\
\hline Lot Size & $:$ LFL & Periode & Lead Time & $: 5$ hari \\
\hline & 1 &
\end{tabular}




\begin{tabular}{l|l}
\hline Kebutuhan Kotor & 3096,65 \\
\hline Kebutuhan Bersih & $(3096,65+365,76)-(3024,56-365,76)=803,61$ \\
\hline Jadwal Rencana Penerimaan & $803,61+365,76=1169,37$ \\
\hline Pelepasan Rencana Pemesanan & 1169,37 \\
\hline
\end{tabular}

Analisa dan perhitungan DRP pada tabulasi kota Blitar untuk 12 periode menghasilkan data sebagai berikut:

Tabel 4. Tabulasi DRP Cabai Rawit Kota Blitar

\begin{tabular}{|c|c|c|c|c|c|c|c|c|c|c|c|c|}
\hline \multicolumn{13}{|c|}{ Blitar } \\
\hline \multirow{2}{*}{\multicolumn{2}{|c|}{$\begin{array}{l}\text { On Hand Balance } \\
\text { Safety Stock }\end{array}$}} & \multirow{2}{*}{\multicolumn{2}{|c|}{$\begin{array}{l}: 3373 \text { ton } \\
: 644 \text { ton }\end{array}$}} & \multirow[b]{3}{*}{ Apr } & \multirow{2}{*}{\multicolumn{2}{|c|}{$\begin{array}{l}\text { Lead Time } \\
\text { Lot Sizing }\end{array}$}} & \multirow{2}{*}{\multicolumn{2}{|c|}{$\begin{array}{l}: 5 \text { hari } \\
: 808 \text { ton }\end{array}$}} & \multirow[b]{3}{*}{ Sep } & \multirow[b]{3}{*}{ Okt } & \multirow[b]{3}{*}{ Nov } & \multirow[b]{3}{*}{ Des } \\
\hline & & & & & & & & & & & & \\
\hline $\begin{array}{l}\text { Past } \\
\text { Due }\end{array}$ & Jan & Feb & Mar & & Mei & Jun & Jul & Agu & & & & \\
\hline $\begin{array}{l}\text { Kebutuhan } \\
\text { Kotor }\end{array}$ & 3096 & 2967 & 2814 & 2984 & 2893 & 2897 & 2654 & 2952 & 3195 & 2975 & 2923 & 2965 \\
\hline $\begin{array}{l}\text { Kebutuhan } \\
\text { Bersih }\end{array}$ & 359 & 1181 & 1089 & 1037 & 1137 & 880 & 918 & 866 & 1328 & 1024 & 636 & 816 \\
\hline $\begin{array}{l}\text { Jadwal } \\
\text { Rencana } \\
\text { Penerimaan } \\
\end{array}$ & 1003 & 1824 & 1733 & 1681 & 1781 & 1524 & 1562 & 1510 & 1972 & 1668 & 1280 & 1459 \\
\hline $\begin{array}{l}\text { Pelepasan } \\
\text { Rencana } \\
\text { Pemesanan }\end{array}$ & 1003 & 1824 & 1733 & 1681 & 1781 & 1524 & 1562 & 1510 & 1972 & 1668 & 1280 & 1459 \\
\hline
\end{tabular}

Dari hasil perhitungan tabulasi tersebut dapat diperoleh analisa jumlah kebutuhan kotor dan kebutuhan bersih pada bulan Januari hingga Desember pada tahun 2015. Hasil perencanaan penerimaan dan pelepasan cabai dalam bentuk hasil analisa data sesuai dengan yang ada pada tabel diatas.

\subsection{Hasil Pengembangan Sistem Informasi}

Hasil implementasi sistem informasi distribusi cabai yang dikembangkan memiliki manfaat untuk membantu pemerintah dalam melakukan pendataan jumlah produksi dan analisa distribusi cabai di Jawa Timur. Petani juga bisa memantau perkembangan produksi dan jumlah konsumsi cabai tiap bulan di Jawa Timur.

Sistem informasi yang dikembangkan memiliki fitur kalkulasi distribusi yang digunakan untuk melakukan perhitungan analisa DRP. Fitur ini hanya dapat diakses oleh pegawai. Pada fitur ini tersedia beberapa atribut diantaranya jenis cabai dan pilihan data kota. Fitur kalkulasi dan data tabulasi distribusi cabai menggunakan metode DRP dapat dilihat pada gambar 5.
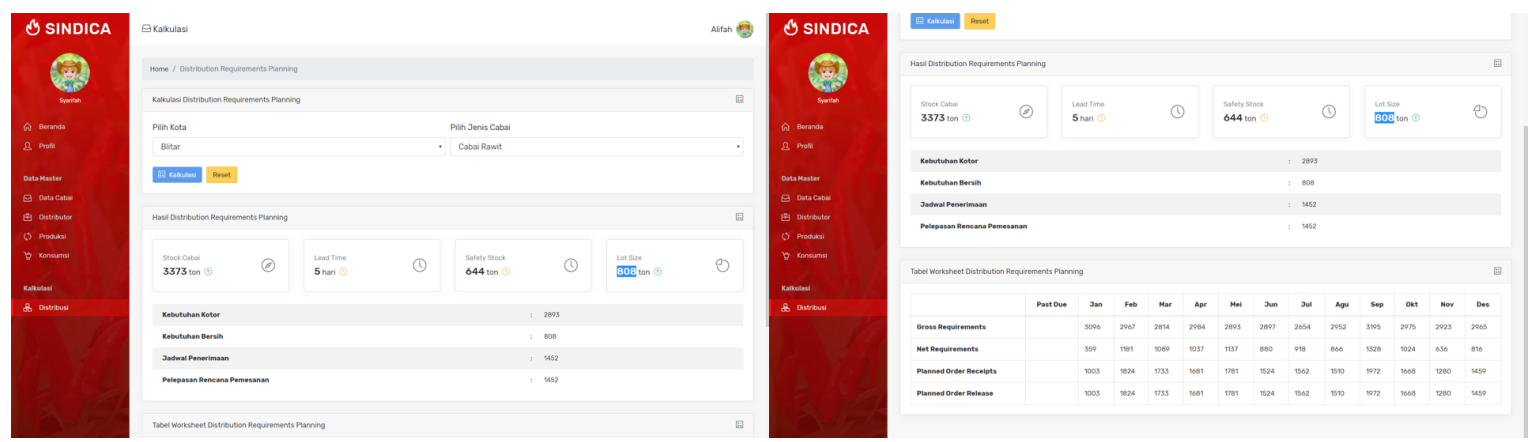

Gambar 3. Fitur Kalkulasi Distribusi

Perhitungan analisa distribusi cabai dijadikan sebagai bahan pertimbangan untuk memenuhi permintaan cabai pada daerah tertentu atau pada waktu tertentu akan dijadikan sebagai bahan evaluasi kerja dalam pendistribusian cabai.

\section{Kesimpulan}

Pola optimal distribusi cabai di Jawa Timur didapatkan dari hasil pengolahan data jumlah produksi dan jumlah permintaan cabai menggunakan metode perbandingan eksponensial. Data permintaan cabai diolah menjadi rata-rata permintaan, tingkat persediaan, kebutuhan kotor, dan safety stock. Pola distribusi yang dihasilkan dari DRP adalah penentuan jumlah kebutuhan bersih serta jadwal pengiriman dan jumlah yang akan diterima pada tiap kota. 
Metode DRP yang diterapkan menghasilkan perhitungan rata-rata jumlah pelepasan rencana pemesanan. Hasil analisa didapatkan dari jumlah produksi sebagai olahan data persediaan cabai, sedangkan konsumsi dijadikan sebagai olahan data permintaan cabai di Jawa Timur. Salah satu kasus untuk kota Blitar yang menjadi penghasil produksi cabai rawit terbanyak berjumlah 1656,69 ton dari jumlah kebutuhan kotor 979,76. Kebutuhan bersih yang didapatkan dari perhitungan safety stock 170,36 dan jumlah persediaan sebanyak 1827,05 ton, maka hasil analisa rencana pelepasan berjumlah 548,97 ton. Sedangkan pelepasan rencana pemesanan berjumlah 6389,69 ton dengan jumlah kebutuhan kotor 3096,65 ton. Hasil nilai perhitungan dari kota yang tersedia akan dijadikan usulan untuk mengisi tabulasi DRP selama tahun 2015.

Implementasi sistem menggunakan model pengembangan waterfall dengan menerapkan metode DRP yang digunakan untuk mendukung supply chain management dalam pengembangan sistem informasi untuk menghasilkan analisa kebutuhan bersih dan kebutuhan kotor cabai pada pusat distributor cabai di Jawa Timur.

\section{Saran}

Penggunaan objek penelitian untuk menghitung nilai DRP harus memiliki data pasti terkait supplier dan distributor agar mampu mendukung supply chain management, sehingga perhitungan memiliki nilai akurasi yang tinggi.

Untuk memperoleh hasil pengoptimalan distribusi, maka proses distribusi harus dimaksimal mulai dari penjadwalan hingga barang diterima oleh konsumen, sehingga data optimal pada metode drp dapat diterapkan pada seluruh kota dengan produksi cabai besar atau cabai rawit.

\section{Daftar Pustaka}

[1] BPS Jatim, B. (2015). Perkembangan Indeks Harga Konsumen/Inflasi Jawa Timur. Jawa Timur Indonesia: Badan Pusat Statistik

[2] Bowersox, D., Closs, D., \& Cooper, M. B. (2012). Supply Chain Logistics Management. New York: McGraw-Hill Education.

[3] Abdillah, A. F. (2009). Perencanaan dan Penjadwalan Aktivitas Distribusi Hasil Perikanan Dengan Menggunakan Distribution Requirement Planning (DRP) (Studi Kasus di UD. Retro Gemilang Internasional - Sidoarjo). Jurnal Skripsi, 1-16.

[4] Pressman, R. S. (2001). Software Engineering: A Practitioner's Approach, Fifth Edition. New York: McGraw-Hill Higher Education (C2001.

[5] Nadjib, B., \& Dauzere, S. P. (2017). Production Planning: New Lot-Sizing Models and Algorithm. Editions Universitaires Europeennes.

[6] Taylor, \& W, B. (2008). Introduction to Manajement Science: Sains Manajemen, Edesi 8, Buku 2. Jakarta: Salemba Empat. 